\title{
EUROPE 2020 - THE NEW STRATEGY FOR SMART, SUSINABLE AND INCLUSIVE GROWTH AND BULGARIAN INDUSTRIAL COMPETITIVENESS
}

\author{
Desislava Petrova, Sofia Dimitrova \\ Technical University of Gabrovo, Faculty of Economics, Department „Management” \\ 4 Hadji Dimitar St, Gabrovo, Bulgaria \\ Ph.: +(359)827-524, e-mail: des_petrova@abv.bg, sofiqdimitrova@abv.bg
}

\begin{abstract}
This paper present one decision on innovation European industry contributes to output, jobs, innovation and exports and is interrelated with service industries. Indeed, many service industries such as transport, health and Information and Communication Technologies (ICT) depend on competitive industry to produce the equipment and hardware which they use [1, 2].
\end{abstract}

Key words: Europe, innovation, policy.

\section{Introduction}

The performance of European industry in terms of exports is largely due to its competitiveness, which is influenced by the business environment, which is in turn created by the regulatory framework both at national and European level:

- the creation of a single market

- a very effective competition policy

- an industrial policy which enables industry to undergo the necessary adjustment processes.

Providing new solutions to customers and remaining at the leading edge of innovation require the protection of related intellectual property, which serves as an incentive to invest in product and process innovation.

EU industry has been seriously affected by the recent economic crisis, revealing a number of structural weaknesses. Industries, together with public authorities, have to undertake the necessary structural adjustments in a politically and socially acceptable way.

Some other longer-term challenges are kept on the policy agenda [1]:

- globalization

- demographic change

- climate and energy.

Policy highlights overview: Europe 2020; European standards; Industrial competitiveness; Innovation; International affairs; Raw materials; Satellite navigation; Security research and development; Single market for goods; Single market for services; Small and medium-sized enterprises (SMEs); Space; Sustainable and responsible business.

\section{Exhibition \\ Europe 2020 - the new strategy for smart, sustainable and inclusive growth}

At the European Council meeting on 26 March 2010, European Union leaders set out their plan for "Europe 2020", a strategy to enhance the competitiveness of the EU and to create more growth and jobs.

The strategy is implemented in close partnership between the Commission and the Member States. Regional, local and non-governmental actors are encouraged to contribute. Member States set out their reform agendas in their National Reform Programmes and report on progress annually. The Commission develops supplementary actions at EU level and maintains a dialogue with the Member States. 
DG Enterprise and Industry contributes to the implementation of the Europe 2020 strategy in particular via the flagship actions on An Industrial Policy for the Globalisation Era, and An Innovation Union, but also contributes to the other flagship actions where relevant. DG Enterprise and Industry monitors and assesses competitiveness policies in the Member States, including areas such as industrial policy, business environment, innovation policy, SME and entrepreneurship policy, better regulation and the internal market for goods. A report on Member States' competitiveness policies and performance will be published annually starting in autumn 2010. More information about the Europe 2020 strategy can be found on the European Commission's central Europe 2020 website.

\section{Europe 2020 flagship: An Industrial Policy for the Globalization Era}

Industry must be placed centre stage if Europe is to remain a global economic leader. This is the core message of the Communication on "An integrated industrial policy for the globalization era" adopted by the European Commission on the 28th of October 2010 on the initiative of Vice-President Antonio Tajani. The Communication, a flagship initiative of the Europe 2020 strategy, sets out a strategy that aims to boost growth and jobs by maintaining and supporting a strong, diversified and competitive industrial base in Europe offering wellpaid jobs while becoming less carbon intensive. It is accompanied by a report on the competiveness performance of individual Member States and the annual European Competitiveness Report.

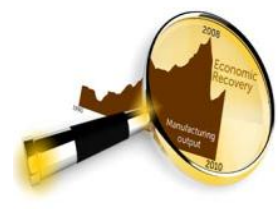

European Commission Vice-President Antonio Tajani, responsible for industry and entrepreneurship said: "Industry is at the heart of Europe and indispensable for finding solutions to the challenges of our society, today and in the future. Europe needs industry and industry needs Europe. We must tap into the full potential of the Single Market, its 500 million consumers and its 20 million entrepreneurs."

In this era of intensifying globalization, the concept of national sectors and industries is obsolete. Coordinated European policy responses are needed. Europe also needs an approach that looks at the whole value chain, from infrastructure and raw materials to after-sales service. Promoting the creation and growth of small and medium-sized enterprises has to be at the core of EU industrial policy. Moreover, the transition to a sustainable economy has to be seized as an opportunity to strengthen competitiveness. Only a European Industrial Policy targeting competitiveness and sustainability can muster the critical mass of change and coordination needed for success. Antonio Tajani added: "There will be no sustainability without competitiveness, and there will be no long-lasting competitiveness without sustainability. And there will be none of them without a quantum leap in innovation!"

Ten key actions for European industrial competitiveness [2]:

- An explicit and thorough "competitiveness proofing" of new legislation will be undertaken. The impact on competitiveness of all policy proposals will be properly analyzed and taken into account.

- "Fitness checks" of existing legislation will identify the potential for reducing the cumulative effects of legislation so as to cut the costs for businesses in Europe.

- The creation and growth of SMEs will be supported by making it easier for them to access credit and help their internationalization.

- A strategy to strengthen European standardization will be presented to meet the needs of industry. 
- European transport, energy and communication infrastructure and services will be upgraded to serve industry more efficiently, taking better into account today's changing competitive environment.

- A new strategy on raw materials will be presented to create the right framework conditions for sustainable supply and management of domestic primary raw materials.

- Sector-specific innovation performance will be addressed through actions in sectors such as advanced manufacturing technologies, construction, bio-fuels and road and rail transport, particularly in view of improving resource efficiency.

- The challenges of energy-intensive industries will be addressed through actions to improve framework conditions and support innovation.

- A space policy will be pursued, developed in collaboration with the European Space Agency and Member States. The Commission will develop a space industrial policy to create a solid industrial base covering the whole supply chain.

- The Commission will report on Europe's and Member State's competitiveness, industrial policies and performances on an annual basis .

Living up to the ambitions of a strong, diversified and competitive industrial base in Europe requires mutually reinforcing policies. This concerns notably the various flagship initiatives developed under the Europe 2020 strategy and strategies such as the one on the EU' s Single Market, adopted on 27 October [3].

\section{Competition policy}

Antitrust rules prohibiting agreements that restrict competition and abuses of dominant positions as well as merger rules are at the heart of EU Competition policy. Control of state aids to enterprises constitutes the third pillar of this policy which is very specific for the EU. Competition policy is crucial for the achievement of the objectives of the Lisbon strategy for growth and jobs, because it creates the conditions for an efficient internal market and is necessary to stimulate knowledge and innovation. The enforcement of EU competition policy is the responsibility of DG Competition. DG Enterprise and Industry is closely associated to such enforcement and it also ensures coherence between the objective to strengthen the competitiveness of EU industry and the competition policy objectives. In addition DG Enterprise and Industry contributes to draft legislative proposals related to antitrust, mergers and State aids and moreover to individual cases with its knowledge of the regulatory and competitiveness situation of specific sectors of industry.

\section{Competitiveness analysis}

The Lisbon Strategy for Growth and Jobs focuses the efforts of the EU on effective response to challenges of demographic change and globalization. Raising the long-term economic potential by increasing productivity growth is one of its fundamental objectives. With the relaunched Lisbon Strategy, the annual Competitiveness Report is designed to contribute to the analytical underpinning of its microeconomic pillar. It presents recent developments of overall competitiveness performance and focuses on issues of economic reform bearing on various drivers of productivity growth and on competitiveness changes in particular industries.
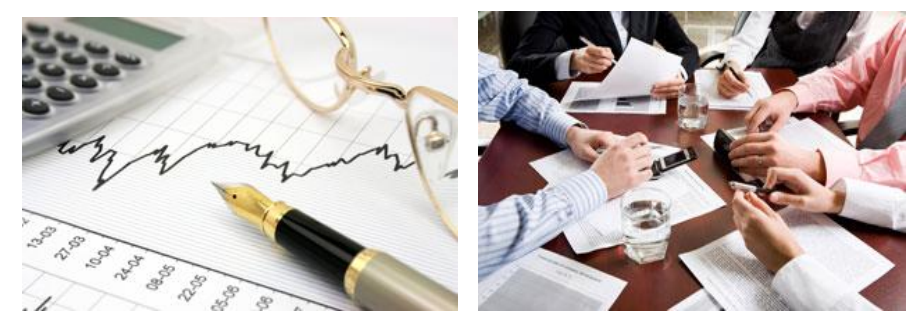

The EU industrial structure is a series of studies which focus on the competitiveness of the EU economy from a sectoral perspective (see last EU industrial structure issue). It provides insights into the performance of each industry and helps to explain the competitiveness of the 
EU economy as a whole. These studies apply the same set of indicators to all sectors. This allows the comparison of performance across sectors. Industrial Policy and Economic Reforms Papers are written by the staff of DG Enterprise and Industry or experts working in association with them. This publication series aims to raise awareness and stimulate the debate in the areas of industrial policy, business environment and economic reforms [1].

\section{Economic crisis}

The bursting of the American subprime mortgage bubble and the bankruptcy of a major American investment bank in September 2008 triggered a dramatic collapse of the global financial system. A meltdown of financial markets could only be avoided through massive interventions by central banks and governments. On financial markets, decisive action coordinated at the European level also showed that a well coordinated response ensures that the outcome can be significantly more than the sum of its parts. Business confidence around the world has plummeted, and so has consumer confidence. Orders have been cancelled on a large scale, export markets around the world have shifted into reverse gear and investment and consumption growth has slowed significantly or even turned negative. In the face of the economic crisis, many businesses have preferred to wait until the dust has settled and the financial market crisis has been resolved, before risking taking on new business opportunities.

\section{Intellectual property rights}

Intellectual property rights (IPR) are important contributors to European competitiveness. These rights, including patents, trademarks, design rights and copyrights, can serve as incentives for research and development, for innovation, and can help users identify trusted producers. We develop policies to help make European businesses aware of these rights and to assess the impact and effectiveness of the use of these rights. We co-ordinate with national administrations and trading partners on these subjects. To this end, DG Enterprise and Industry has launched projects that include support to national intellectual property offices improving their business support services about IPR (IPeuropAware), and a pilot project to help small and medium-sized businesses facing IPR problems in, or arising from, China (China IPR SME Helpdesk).

\section{European standards}

Standardisation is the voluntary process of developing technical specifications based on consensus among all interested parties (industry including Small and Medium-sized Enterprises (SMEs), consumers, trade unions, environmental Non Governmental Organisations (NGO), public authorities, etc). It is carried out by independent standards bodies, acting at national, European and international level. While the use of standards remains voluntary, the European Union has, since the mid-1980s, made an increasing use of standards in support of its policies and legislation. Standardisation has contributed significantly to the completion of the Internal Market in the context of 'New Approach' legislation, which refers to European standards developed by the European standards organisations.Furthermore, European standardisation supports European policies in the areas of competitiveness, Information and Communication Technologies (ICT), innovation, interoperability, environment, transport, energy, consumer protection, etc. Standardisation is an excellent tool to facilitate international trade, competition and the acceptance of innovations by markets. A key challenge for European standardisation is to strengthen its contribution to the competitiveness of Small and Medium-sized Enterprises (SMEs). Standardisation supports market-based competition, so as to achieve objectives such as the interoperability of complementary products and services, or to provide agreed test methods and requirements for health, safety, organisational and environmental performance. Through the development of European standards and the withdrawal of conflicting national standards, standardisation has played a leading role in the achievement of a Single Market for goods. Standardisation also has a public interest dimension, in particular with regard to the issues of 
health, safety, security and of the environment. For this reason, the European Union has an active standardisation policy, which promotes standardisation in support of better regulation, and as an instrument for the competitiveness of European industry. This policy is centred upon the recognised European standardisation system, and a partnership to implement the 'New Approach'.

\section{Innovation}

In a remarkably short time, economic globalisation has changed the world's economic order, bringing with it new challenges and opportunities [2] . Europe cannot compete in this new environment unless it becomes more innovative and responds more effectively to consumers' needs and preferences. The European Union possesses extraordinary potential for innovation. Europe has a longstanding tradition of producing breakthrough inventions; it has a wealth of creative people and can build on its cultural diversity. It has laid the foundations for one of the largest single markets in the world, where innovative products and services may be commercialised on a large scale. Historically it has a strong and responsible public sector, which should be capitalised on. The European Commission is formulating, influencing and, where appropriate, implementing policies and programmes to increase Europe's innovativeness. The Commission is trying to make sure innovation is thoroughly understood and approached comprehensively, thereby contributing to greater competitiveness, sustainability and job creation.

6.1. Innovation - Facts, figures and analysis - to make sure implemented innovation policies yield tangible results, the European Commission makes use of a number of tools enabling it to collect data on innovation performance in Europe.

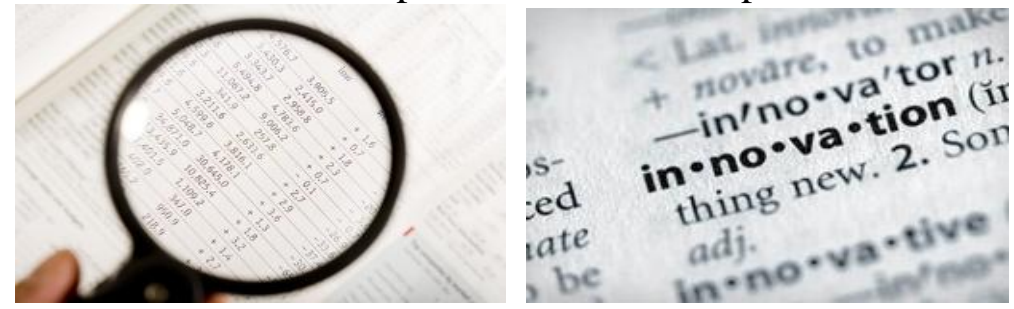

These facts, figures and analyses provide insight into the strengths and weaknesses of national innovation systems in EU member states and other countries. They also help in understanding specific drivers and barriers to innovation at sector level. The data includes assessments of innovation performance, policy responses, innovation policy governance and innovation policy trends across Europe.

6.2. Innovation Policy $[1,2]$ - about helping companies to perform better and contributing to wider social objectives such as growth, jobs and sustainability. There are many policy tools available to achieve this, ranging from establishing supportive framework conditions (e.g. human resources, an internal market, intellectual property) to facilitating access to finance, policy benchmarking and enabling collaboration or stimulating demand, for instance, through regulation, standards and public procurement. The rationale for European innovation policy is strongest where it is oriented toward addressing the most significant challenges facing society today. The main current Community innovation policy is the "Broad-based innovation strategy for the EU". It points the way to accompanying industry-led and society-driven innovation with competitiveness and public policies at all levels as a key element of the renewed Lisbon strategy for growth and jobs.

The strategy singles out ten priority actions in a roadmap for action at national and European levels. The Commission plans in particular to encourage the emergence of "lead markets", where public authorities facilitate industry-led innovation by creating the conditions for a successful market uptake of innovative products and services in a focused way in areas such as e-health, internal security, eco-innovation and eco-construction. 
6.3. Future EU Innovation Policy The December 2008 European Council called for a European Plan for Innovation. As a first step the Commission presented possible short term actions in response to the economic crisis and an assessment of achievements made under the Broad Based Innovation Strategy, accompanied by reviews of the Lead markets Initiative, innovation in services, financing innovation in SMEs and the effectiveness of innovation support measures. This provided the basis for consultations (see below) and debate on the directions and possible measures to be included in a European plan for innovation that could be presented in autumn 2010. The reflections on future innovation policy are an integral part of the Europe 2020 strategy.

Public consultation on Community innovation policy seeks to follow up the findings of the Commission Communication "Reviewing Community innovation policy in a changing world" and two previous consultations, one on the effectiveness of innovation support in Europe and one on design as a driver ofuser-centred innovation. It will serve as an input to the preparation of a new European innovation plan, as called for by the European Council. Business Panel on future European innovation policy and its blog consultation has been established by DG Enterprise and Industry to provide inputs from a business perspective on priorities for future EU innovation policy. From 7 July to 31 August 2009, the panel was holding an open online consultation on its ideas and proposals through the Innovation Unlimited blog.
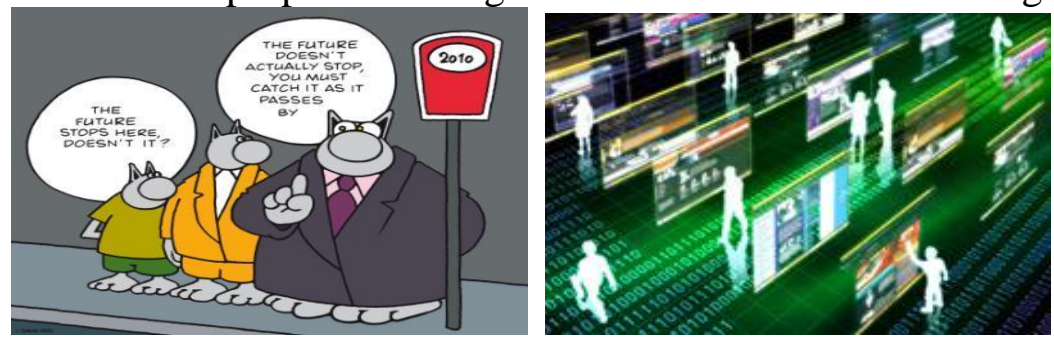

\subsection{Innovation - Knowledge and Technology Transfer}

Generating new knowledge and turning it into new products and services is important to maintaining and enhancing Europe's competitiveness. It is fundamental that researchers and industry work closely together and maximise the social and economic benefits of new ideas. Transforming research results into new commercial products is a complex process, involving a broad range of stakeholders. It is not enough to simply increase public investment in research; it is important to create a framework to facilitate the process of knowledge transfer by removing the barriers which hinder collaboration between research and industry in order for Europe to operate as a single market for knowledge. In its broad-based innovation strategy, the Commission has identified the importance of improving the transfer of knowledge between public research institutions and third parties, including industry and civil society organisations, as one of ten key areas for action [3].

\subsection{Innovation - ICT and other key technology enablers}

In today's economy, it is clearer than ever that information and communication technology (ICT) is the most important driver of innovation and competitiveness. In addition to ICT, other key enabling technologies are more and more revolutionising the products and services on offer as well as the way business is conducted in Europe and this revolution will continue in the future. The Enterprise and Industry Directorate-General pursues a range of policies to enhance the use of ICT and the deployment of other key technology-enablers that advance the economy, create innovation and deliver sound competitiveness benefits. Learn more about our activities in this area by visiting the pages of this website related to ICT for Competitiveness \& Innovation. 


\section{Summary}

Innovation and Innovation Union - The European Commission's "Innovation Union" has been presented. It sets out a strategic approach to innovation. This Europe 2020 flagship will boost Europe's research and innovation performance by speeding up the process from ideas to markets. The Commission proposes a series of actions to put innovation at the heart of EU economy and society for the benefit of companies and citizens. The new "Innovation partnerships" will generate breakthroughs in areas of concern for the citizens such as climate change, energy efficiency and healthy living. The success will depend on the commitment of all actors involved in innovation cycle.

\section{References}

1. Petrova D., Management on firm - theory and practices, monograph, Education „EKC - PRES” - Gabrovo, Bulgaria, 2010, ISBN 978-954-490-112-7

2. Petrova D., Higher productivity of labor and competitive power on firm used motivation of staff through involvement in concept oriented change processes, $38^{\text {th }}$ IGIP Symposium $-Q^{2}$ of $E^{2}$, Quality and Quantity of Engineering Education, September 6-9, 2009, Graz, Austria, Fachhochschule der Wirtschaft CAMPUS 02 - Graz, ISBN: 978-3-85295-035-8, pp. 291-299

3. www.europe.com 